Original Research Paper

\title{
Pemberdayaan Masyarakat Desa Sukamakmur Kabupaten Jember dalam Budidaya Lobster Air Tawar
}

\author{
Basuki $^{1}$, Nurul Dwi Novikarumsari ${ }^{2}$, Indah Ibanah $^{3}$, Indri Fariroh ${ }^{4}$

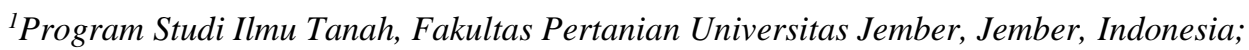 \\ ${ }^{2}$ Program Studi Penyuluh Pertanian, Fakultas Pertanian Universitas Jember, Jember, Indonesia; \\ ${ }^{3}$ Program Studi Penyuluh Pertanian, Fakultas Pertanian Universitas Jember, Jember, Indonesia; \\ ${ }^{4}$ Program Studi Agronomi, Fakultas Pertanian Universitas Jember, Jember, Indonesia.
}

https://doi.org/10.29303/jpmpi.v3i2.954

Sitasi: Basuki., Novikarumsari, N. D., Ibanah, I \& Fariroh, I. (2021). Pemberdayaan Masyarakat Desa Sukamakmur Kabupaten Jember dalam Budidaya Lobster Air Tawar. Jurnal Pengabdian Magister Pendidikan IPA, 4(3)

\section{Article history}

Received: 28 Agustus 2021

Revised: 10 September 2021

Accepted: 12 September 2021

*Corresponding Author: Basuki, Program Studi Ilmu Tanah Fakultas Pertanian Universitas Jember, Jember, Indonesia; Email: basuki@unej.ac.id

\begin{abstract}
Sukamakmur Village is a village located in Ajung District, Jember Regency with residents making a living as farmers and cultivating freshwater fish. The location of Sukamakmur Village is very prospective for freshwater fish cultivation because of its strategic location in getting water, and the type of fish being cultivated is catfish. In the last period, most of the people who cultivate catfish have gone out of business due to increasing feed prices while the selling value of catfish is unable to cover. The purpose of this community service program is to increase the standard of living and welfare of the people of Sukamakmur Village through the cultivation of freshwater crayfish as a substitute for catfish commodities. The method used for service program activities is through socialization, training, mentoring, and evaluation approaches. The results of the activity show that the community is enthusiastic in implementing freshwater crayfish cultivation because the cultivation method is very easy and requires low costs. Another result obtained is that the community can start new businesses, especially those that have gone out of business due to catfish cultivation so that they can bounce back in increasing their income.
\end{abstract}

Keywords: Cultivation, Freshwater Lobster, Income Increase, Catfish dibandingkan udang windu dan udang galah bila dilihat dari presentase daging yang tinggi, tahan terhadap penyakit, daya memijah 3-5 kali dalam setahun, bertahan dalam kondisi air yang keruh (Muhammad Junaidi et al., 2021). Selain itu lobaster air tawar memiliki nikai jual sama dengan lobster air laut, dalam pengemasan tetap segar tanpa air sampai tujuan. Dilihat dari makanan, jenis lobster air tawar termasuk dalam kategori omnivora, sehingga mudah dalam penyediakan makanan(Cokrowati et al., 2020; Ihsan et al., 2020).

Desa sukamakmur bagian dari Kecamatan Ajung Kabupaten Jember. Mata pencaharian penduduk sebagian besar bertani, dan beternak. Ternak yang di kembangkan yaitu ternak unggas dan perikanan. Perikanan di Desa Sukamakmur 
didukung oleh wilayah desa yang dialiri air irigasi dan kondisi wilayah cekungan sehingga untuk kebutuhan penyediaan air sangat mudah(Muhamad Junaidi et al., 2020; Muhammad Junaidi et al., 2021). Perikanan menjadi sektor utama yang menjadi lokomotif perekonomian penduduk dalam mendorong pembangunan di desa ini.

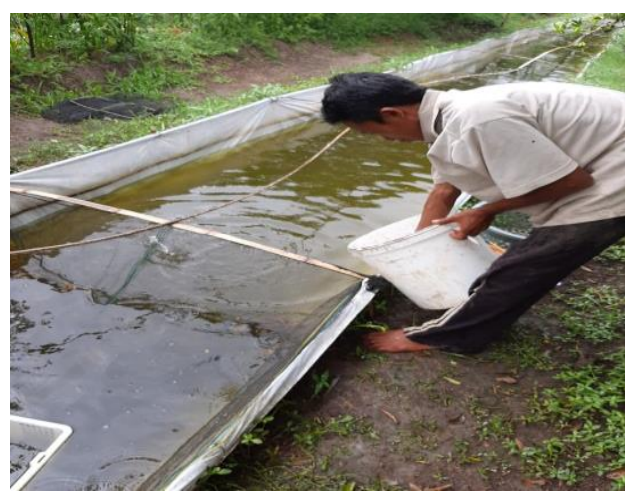

Gambar 1. Kolam Budidaya Ikan Air Tawar

Budidaya perikanan yang utama dan sebagian besar penduduk lakukan di Desa Sukamakmur yaitu ikan lele. Kelebihan budidaya Ikan lele menurut para pembudidaya karena memiliki pasar yang mudah dan di ambil oleh tengkulak langsung dalam kolam. Kurun waktu 2 tahun terakhir, budidaya ikan lele mengalami kemerosotan dan sebagian pembudidaya gulung tikar karena antara input dan output yang didapatkan tidak sesuai. Ketidaksesuaian tersebut disebabkan oleh harga pakan berupa konsentrat naik bisa sampai 9000 rupiah per kilogram, sedangkan harga jual lele setelah 3 bulan stagnan di kisaran 6000-8000 rupiah per kilogram. Selain itu, sifat lele yang kanibal saat pemberian pakan yang kurang, menyebabkan penurunan produksi dan hasil panen. Berdasarkan situasi diatas perlu inovasi dalam meningkatkan gairah masyarakat dalam memanfaatkan lahan kolam ikan yang sebelumnya kosong untuk komoditas lain berupa lobster air tawar yang memiliki keunggulan terutama dari nilai ekonomis untuk meningkatkan taraf hidup masyatakan Desa Sukamakmur.

\section{Metode}

\section{Tempat dan Waktu Pelaksanaan}

Kegiatan pengabdian masyarakat dilaksanakan di Desa Sukamakmur Kecamatan Ajung Kabupaten Jember Propinsi Jawa Timur.
Waktu pelaksanaan pada bulan Agustus 2021September 2021.

\section{Sasaran Pelaksanaan}

Kegiatan pengabdian masyarakat dengan judul Pemberdayaan Masyarakat Desa Sukamakmur Kabupaten Jember Dalam Budidaya Lobster Air Tawar memiliki sasaran yaitu kelompok peternak lele yang gulug tikar, pemudapemudi karang taruna, perangkat desa, warga lainnya di Desa Sukamakmur.

\section{Metode dan Pendekatan Pelaksanaan}

Metode kegiatan pengabdian masyatakat yaitu dengan metode sosialisasi dan pelatihan. Metode tersebut dituangkan dalam langkah-langkah kegiatan yang disepakati bersama meliputi sosialisasi dan pelatihan budidaya lonster air tawar yang terbagi atas 3 tahap yaitu persiapan, pelaksanaan program, dan evaluasi program (Gambar 2.). Adapun penjabaran dari tiap kegiatan sebagai berikut:

\section{Persiapan}

Kegiatan persiapan meliputi pemilihan lokasi kegiatan, analisis situasi, penjaringan dana, pembuatan roadmap kegiatan, persiapan alat dan bahan yang digunakan dalam pelaksaan program.

2. Pelaksanaan Program

Pelaksanaan program terbagi atas penyuluhan dan pelatihan.

> Tahap 1 dalam pelaksanaan program yaitu Penyuluhan diawali dengan melakukan sosialisasi jenis-jenis lobster, perbedaan jantan-betina lobster, perawatan lobster, asupan nutrisi lobster, dan pemanenan lobster.

Tahap ke 2 dalam pelaksanaan program yaitu pelatihan terkait pemilihan lobster yang baik untuk dibudidayakan, cara tebar lobster dalam kolam, dan cara perawatan kobster dalam kolam.

3. Pendampingan

Pendampingan dilakukan saat sosialisasipaska pelatihan dengan turut aktif dalam pemecahan masalah yang terjadi saat para peserta mulai mempraktekkan sampai panen lobster. Dalam kegiatan pendampingan ini peserta dengan pengusul tidak harus bertemu tatap muka tetapi dapat melalui pemanfaatan alat komunikasi seperti media 
telepon, whatsaap, sms, atau media lain yang mendukung dalam kelancaran pemdampingan.

\section{Evaluasi}

Evaluasi dilaksanakan pada akhir kegiatan pengabdian masyarakat dengan melihat kelayakan ekonomi melalui diskusi informasi, forum FGD, atau refleksi.

\section{Hasil dan Pembahasan}

Kegiatan sosialisasi dilaksanakan padan bulan Agustus 2021 di ruang pertemuan kantor kepala desa Sukamakmur Kecamatan Ajung Kabupaten Jember. Kegiatan sosialisasi dihadiri oleh 17 peserta yang terdiri atas kelompok peternak lele yang gulug tikar, pemuda-pemudi karang taruna, Bumdes, perangkat desa, warga lainnya yang tertarik atas budidaya lobster air tawar (Gambar 2.). Ketertarikan peserta dalam kegiatan sosialisasi akan menjadi hal penting dalam keberlanjutan program pengabdian. Peserta sosialisasi tertarik terkait dengan budidaya lobster mengingat lebih mudah dan membutuhkan biaya yang ekonomis tetapi memiliki nilai jual yang tinggi. Ketertarikan tersebut ditunjukaan dengan antusias peserta dalam proses tanya jawab. Topik tanya jawab dari peserta kepada narasumber mulai dari budidaya lobster, mendapatkan bibit lobster, prospek lobster, dan cara menjual bilamana lobster sudah siap panen. Peran dari peserta kegiatan sosialisasi sangat penting dan memiliki nilai yang positif bilamana disertai dengan kesadaran dan tanggung jawab yang tinggi dalam mensukseskan kegiatan sesuai dengan peran masing-masing (Syukur et al., 2018). Kepala bumdes sekaligus pembudidaya lele yang sudah lama berhenti sangat tertarik untuk mengembangkan budidaya lobster, selain itu bersedia untuk memanfaatkan kolam lele yang selama ini terbengkalai.

Kegiatan sosialisasi tidak akan berguna bilamana tidak ada pelatihan. Pelatihan dilakukan pada tanggal 1-10 september 2021 dengan dihadiri oleh 20 peserta. Pelatihan dilakukan untuk meningkatkan keterampilan, pengetahunan, teknologi, dan manajerial budidaya (Junaidi et., al. 2021). Menurut Sunhaji (2013)., pembelajaran orang dewasa memperhitungkan kepentingan peserta didik bukan hanya pertimbangan pendidik karena belajar merupakan suatu proses dalam meningkatkan pengetahuan yang dilakukan sepanjang hayat. Pelatihan dilakukan dengan pemberian brosus dan praktek langsung dalam melihat morfologi lobster baik jantan maupun betina, perawatan kolam sebagai media budidaya yang baik untuk lobster, dan memberikan makanan lobster baik waktu dan jenis makanan yang bernutrisi tinggi.

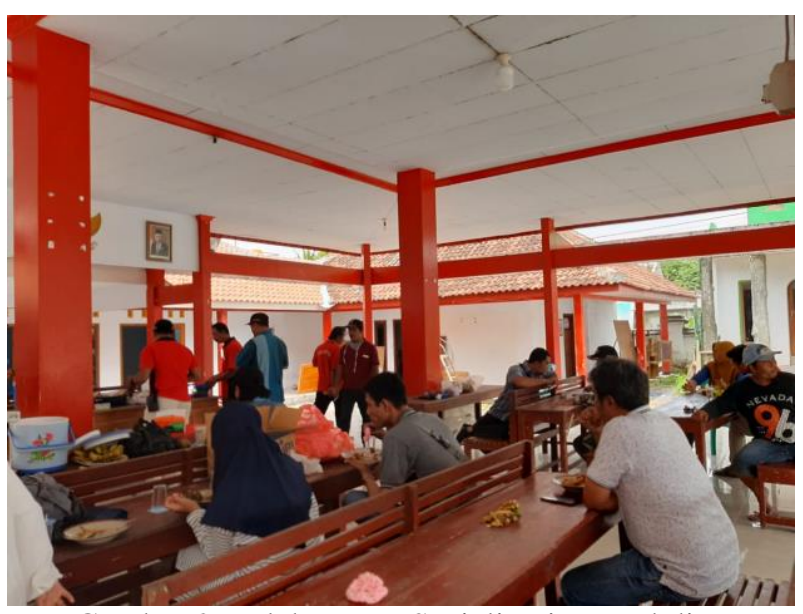

Gambar 2. Pelaksanaan Sosialisasi Pengabdian masyarakat

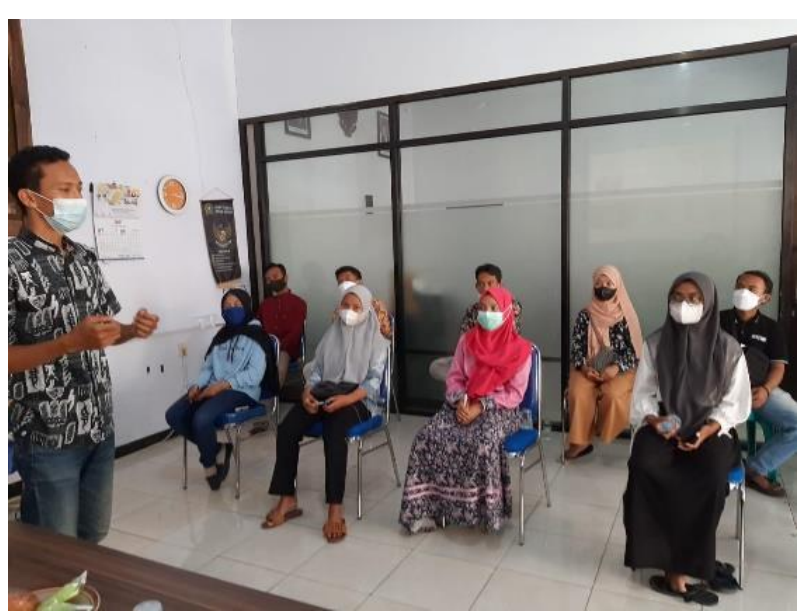

Gambar 3. Pelatihan Cara Membedakan Jenis Kelamin Lobster

Benih lobster di dapat dari SMK kelautan puger Kabupaten Jember dengan garga per ekor dengan 3-4 cm seharga 8000 rupiah. Pemberian benih lobster per peserta sebanyak 2 pasang, dan selain itu juga diberikan pakan pellet sebagai modal dasar minat peserta dalam budidaya lobster. Pendampingan dilakukan sepanjang waktu pengabdian dan setelah pengabdian berlangsung dapat melalui media telpon, whatsaap atau media lain yang dapat meningkatkan kemandirian dalam mengembangkan budidaya lobster air tawar. 
Pendampingan dapat meningkatkan pemahaman peserta dalam penanganan masalah yang timbul dalam proses budidaya lobster air tawar.

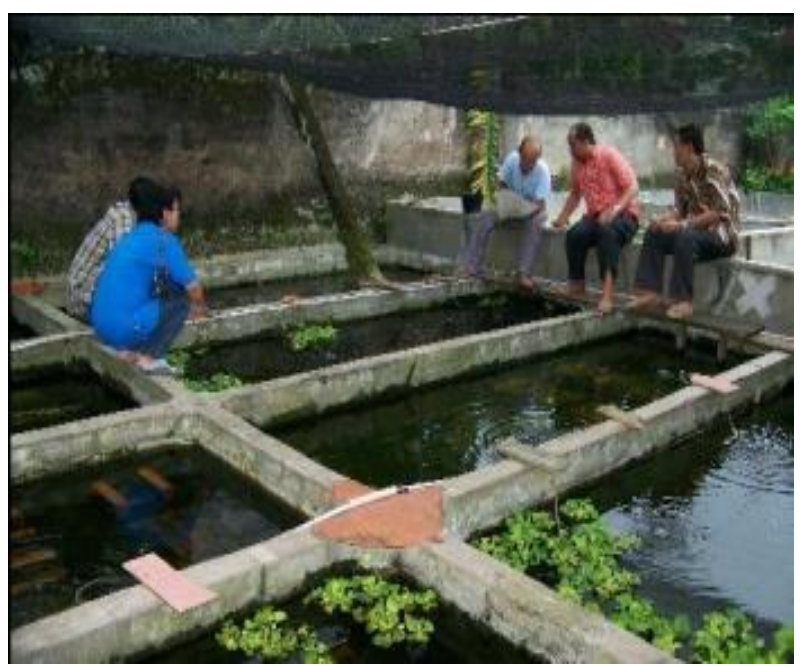

Gambar 4. Penyebaran Bibit Lobster

Hasil kegiatan pengabdian dilakukan dengan evaluasi pemahaman peserta dalam budidaya lobster air tawar melalui kegiatan pengisian daftar kuisioner terkait pemanfaatan materi dan keberlanjutan program kegiatan. Responden berjumlah 17 orang.

\section{Manfaat Materi}

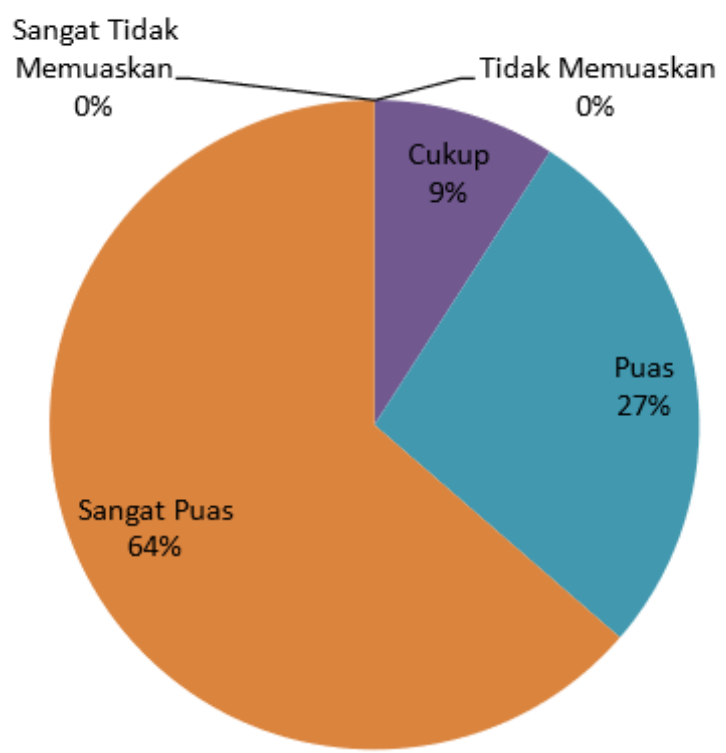

Gambar 5. Hasil Kuisioner terkait manfaat materi

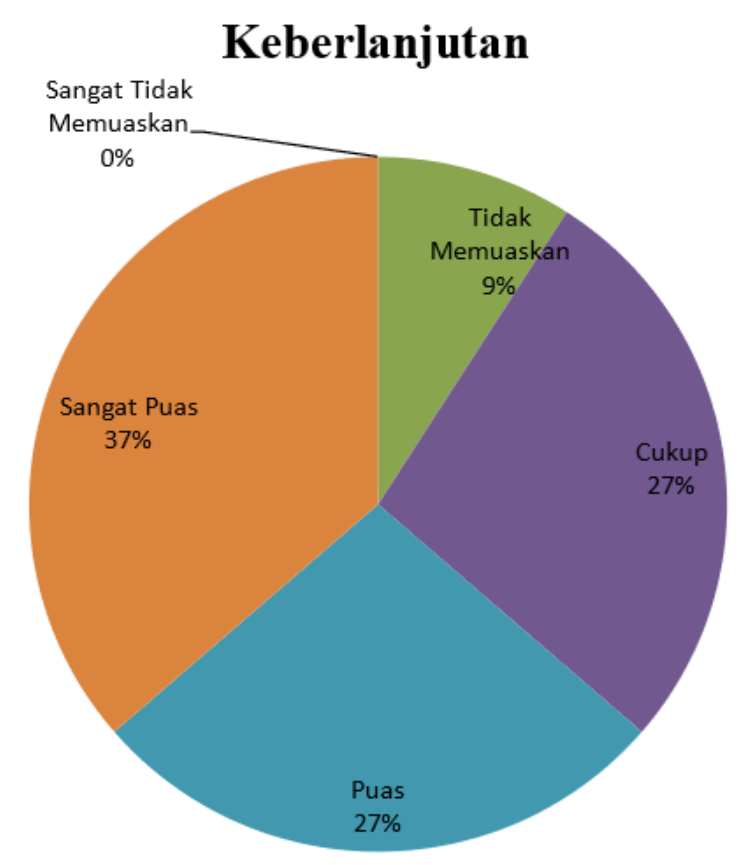

Gambar 6. Hasil Kuisioner Keberlanjutan Program

Hasil pengamatan terkait kemanfaatan program pengabdian terkait Pemberdayaan Masyarakat Desa Sukamakmur Kabupaten Jember Dalam Budidaya Lobster Air Tawar, peserta sangat puas terhadap materi sebesar $64 \%$, kategori puas sebesar $27 \%$, kategori cukup puas $9 \%$, dan sisanya kategori tidak memuaskan dan tidak sangat memuaskan. Sedangkan hasil keberlanjutan program $37 \%$ mendukung kegiatan dengan presentase $37 \%$ sangat puas, $27 \%$ puas, $27 \%$ cukup, dan $9 \%$ tidak memuaskan. Kuisioner tersebut menunjukkan bahwa materi budidaya lobster dalam meningkatkan taraf hidup masyarakat melalui animo masyarakat dan perangkat Desa Sukamakmur dalam mendukung pengabdian masyarakat ini. Diharapkan dengan selesainya program ini, keberlanjutan yang didukung dengan kuisioner dapat terus dilakukan secara luas, sehingga tujuan dalam meningkatkan taraf hidup masyarakat meningkat.

\section{Kesimpulan}

judul Pemberdayaan Masyarakat Desa Sukamakmur Kabupaten Jember Dalam Budidaya Lobster Air dapat meningkatkan solusi terutama yang gulung tikar budidaya lele. Dari kegiatan pengabdian ini dapat dirumuskan kesimpulan sebagai berikut: 
1. Budidaya lobster menjadi haraban baru bagi masyarakat desa Sukamakmur untuk meningkatkan pendapatan dan mata pencaharian yang berkelanjutan.

2. Budidaya lobster sebagai semangat baru bagi penduduk desa Sukamakmur yang gulung tikar budidaya lele karena input dan output yang tidak seimbang.

\section{Ucapan Terima Kasih}

Tim pengabdian masyarakat menyampaikan terimakasih kepada Universitas Jember melalui pemberian bantuan dana untuk pelaksanaan pengabdian masyarakat di Desa Sukamakmur melalui hibah Desa Binaan tahun anggaran 2021.

\section{Daftar Pustaka}

Cokrowati, N., Setyowati, D. N., Diniarti, N., Mukhlis, A., Perwitasari, W. K., \& Amiri, M. (2020). Pembuatan Pakan Pellet Moist Berbahan Baku Lokal Untuk Budidaya Lobster di Karamba Jaring Apung. Jurnal Pengabdian Magister Pendidikan IPA, 3(1), 2-6. https://doi.org/10.29303/jpmpi.v3i1.422

Ihsan, M., Priyambodo, B., \& Muliasari, H. (2020). Pelatihan pembuatan pakan gel berbasis bahan lokal sebagai pakan alternatif budidaya lobster di Pulau Lombok. Transformasi: Jurnal Pengabdian Masyarakat, 16(1), 1-11. https://doi.org/10.20414/transformasi.v16i1.2 106

Junaidi, Muhamad, Dwi Hari Setyono, B., \& Azhar, F. (2020). Demplot Budi Daya Lobster dan Kerang Mutiara secara Terintegrasi dalam Rangka Penguatan Kemitraan Masyarakat Lombok Utara. Agrokreatif: Jurnal Ilmiah Pengabdian Kepada Masyarakat, 6(3), 249259.

https://doi.org/10.29244/agrokreatif.6.3.249259

Junaidi, Muhammad, Cokrowati, N., \& Diniarti, N. (2021). Peningkataan Produktivitas Keramba Jaring Apung dengan Budidaya Kerang Mutiara Sistem Terintegrasi di Kabupaten Lombok Utara. Jurnal Pengabdian Magister Pendidikan

IPA, $4(2)$. https://doi.org/10.29303/jpmpi.v4i2.696

Syukur, A., Khaeruddin, K., \& Yamin, M. (2018). Penerapan Teknologi Budidaya Ramah Lingkungan Pada Nelayan Kecil di Desa Ketapang Raya Lombok Timur. Jurnal Pengabdian Magister Pendidikan IPA, 1(1). https://doi.org/10.29303/jpmpi.v1i1.210

Triarso Imam, S. P. P. (2019). Pengembangan Budidaya Perikanan Produktif Berkelanjutan Sistem IMTA (Integrated Multi-Trophic Aquaculture) (Studi Kasus di Kep. Karimunjawa, Jepara). Life Science, 8(2), 192-199. 